\title{
Challenges and Opportunities in Lidar Remote Sensing
}

\author{
Zhien Wang ${ }^{1 *}$ and Massimo Menenti ${ }^{2,3 *}$ \\ ${ }^{1}$ Laboratory for Atmospheric and Space Physics and Department of Atmospheric and Oceanic Sciences, University of Colorado, \\ Boulder, CO, United States, ${ }^{2}$ Department of Geoscience and Remote Sensing, Faculty of Civil Engineering, Delft University of \\ Technology, Delft, Netherlands, ${ }^{3}$ State Key Laboratory of Remote Sensing Science, Aerospace Information Research Institute, \\ Chinese Academy of Sciences, Beijing, China
}

Keywords: lidar, atmospheric science, terrain, terrestrial ecology, cryospheric discovery, lidar data assimilation, earth system science

\section{INTRODUCTION}

Lidar (light detection and ranging, also LIDAR, LiDAR, and LADAR) advanced rapidly after the invention of the laser in 1960 (Maiman, 1960; Woodbury et al., 1961; Smullin and Fiocco, 1962; Schotland, 1966; Cooney, 1968; Melfi et al., 1969). A variety of lidar technologies have been developed to provide atmospheric and surface properties during the last 60 years (Fiocco and Smullin, 1963; Weitkamp, 2005; Kashani et al., 2015) to support advancements in digital models of terrain, cryospheric discovery, terrestrial ecology, hydrology, atmospheric science, and oceanography. The successful lidar operations of NASA's Cloud-Aerosol Lidar and Infrared Pathfinder Satellite Observations (CALIPSO, Winker et al., 2010) and Ice, Cloud, and land Elevation Satellite (ICESat, Markus et al., 2017) and ESA's Aeolus wind satellite (Kanitz et al., 2020) highlight a new era of lidar developments and applications. Measurement concepts and technology are evolving simultaneously in different directions. Doppler lidars with different measurement capabilities are widely adopted by the wind energy industry (Krishnamurthy et al., 2012; Bos et al., 2016). Miniaturization and photon-counting instruments are opening completely new areas in science and applications with cheaper ground-based instruments and ultra-light, affordable drones. 3D surface mapping by imaging lidar is required across a broad - spectrum of applications, from construction projects ( $\mathrm{Pu}$ and Vosselman, 2009) to understand land atmosphere interactions (Colin et al., 2010; Faivre et al., 2017). The higher performance achievable by a time-correlated single-photon counting implemented in a multiple beams system has been documented (see e.g. Chen et al., 2018). A growing range of terrestrial, unmanned aerial vehicle (UAV or 'drone') (González-Jorge et al., 2017) and airborne scanning systems is attracting a wide community of professionals to deploy such systems to support large engineering projects and to monitor in great detail infrastructures of all sorts, from bridges to buildings and urban canyons (Wang et al., 2013; Roca et al., 2016). The role of lidar will be increasingly important in the future. Although there are many potentials for new lidar technology advancements, lidar activities are gradually shifting from technology developments to applications. Thus, discussions here mainly focus on the opportunities and challenges for advancing lidar applications in the future. Accepted: 07 January 2021 Published: 04 March 2021

Citation:

Wang $Z$ and Menenti M (2021) Challenges and Opportunities in Lidar Remote Sensing. Front. Remote Sens. 2:641723. doi: 10.3389/frsen.2021.641723

\section{LOW COST AND TURNKEY ATMOSPHERIC LIDAR SYSTEMS TO SUPPORT OPERATIONAL APPLICATIONS}

To support operational lidar applications, transferring research lidars into turnkey systems and reduce their costs are necessary steps. During the last 20 years, advances in industrial lasers improved 
lidar system reliability and lowered system development and operational cost. Recent wind energy developments accelerated the low cost and turnkey Doppler lidar developments. Now micropulse type lidars are available for routine aerosol and water vapor measurements (Welton et al., 2001). Compact Raman lidars were demonstrated for airborne and groundbased operations (Wu et al., 2016; Lange et al., 2019). However, we still need to overcome many issues . First, atmospheric lidar system designs have to consider providing quantitative and automatic or semi-automatic lidar data processing. Second, enhancing system stability has to be one of the high priorities. Micropulse lidar (MPL) is one of the successful lidar designs to support aerosol and cloud observations, and the DOE/ARM program operated MPLs for the last 20 years. However, temporal variations of MPL system performance, especially in near range alignment, makes it difficult to use long-term MPL data to provide consistent long-term aerosol products. Third, it is critical to consider improving near-surface (within $500 \mathrm{~m}$ ) measurements for ground-based lidar system design. Due to incomplete overlapping between the transmitting and receiving optical system, near-surface measurements of aerosol, water vapor, and temperature are often unavailable or with large uncertainties. However, these near-surface measurements are critical for many applications. Future lidar systems with ceilometer's robustness and increased capabilities will enhance our atmospheric monitoring capabilities (Engelmann et al., 2016; Wu et al., 2016; Stillwell et al., 2020).

\section{LIDAR NETWORKS TO SUPPORT RESEARCH AND OPERATIONS}

The spatial variability of atmospheric properties and processes limits the values of single lidar measurements. Many existing lidar research networks, such as the European Aerosol Research Lidar Network (EARLINET, Pappalardo et al., 2014), the Asian Dust Network (AD-Net, Sugimoto et al., 2016), the National Aeronautics and Space Administration Micropulse lidar network (MPLNET, Welton et al., 2001), and the Network for the Detection of Atmospheric Composition Change (NDACC, De Mazière et al., 2018), were developed in the past with different success. For future operation supports, network lidar operations are critically needed (Bösenberg and Hoff, 2007; National Research Council, 2009; Wulfmeyer et al., 2015). Differentscale networks are needed to meet various application needs. Regional lidar networks can monitor urban air quality and cover the data gaps for weather models (Langford et al., 2018). A global lidar network is necessary to study stratospheric and mesospheric variations (Chu and Yu, 2017; De Mazière et al., 2018).

Robust and cost-effective lidar systems are essential to support long-term operational lidar networks in the future. Global ceilometer (a simple elastic lidar) network is the most successful lidar network to support operation so far. Current efforts in using ceilometer vertical profiles to characterize the Planetary Boundary Layer (PBL) structure will further empower the ceilometer network (Hicks et al., 2019). Lidar technologies for temperature, water vapor, and wind measurements, which are regarded as a high priority to fill observation gaps (especially within $\mathrm{PBL}$ ) to improve weather and air quality prediction, are mature for operational lidar networks in the near future (Goldsmith et al., 1998; Nehrir et al., 2011; Reichardt et al., 2012; Weckwerth et al., 2016; Wu et al., 2016). Ocean-based lidar deployments, on buoys, island, ice, and commercial ships, are needed to fill critical measurement gaps (Mariage et al., 2017). To fully unleash the power of lidar network observations, the quality control, archive, and open access of lidar data will be essential.

\section{LIDAR DATA ASSIMILATIONS TO IMPROVE WEATHER AND AIR QUALITY FORECAST}

Lidar data can be used to improve weather and air quality forecast through data assimilations. Studies show that assimilating Doppler lidar wind measurements can improve not only short-time resource predictions of wind farmers (Würth et al., 2019; Perr-Sauer et al., 2020) but also mesoscale weather forecast (Pu et al., 2010; Kawabata et al., 2014). Assimilating Raman lidar water vapor and temperature measurements can fill current observation gaps in $\mathrm{PBL}$ to improve model performance (Wulfmeyer et al., 2006; Chipilski et al., 2019; Leuenberger et al., 2020).

While having operational lidar networks and maintaining high-quality data collections are necessary for operational data assimilations, further developments of assimilation methods to effectively use highly temporally and vertically resolved lidar measurements are still needed. Although it is straightforward to assimilate lidar water vapor, temperature, and wind measurements by adjusting corresponding model variables, fully using high temporal resolution observations requires further investigations. Assimilating lidar aerosol measurements can improve PM2.5 forecast (Cheng et al., 2019; El Amraoui et al., 2020). Using PBL structure information contained within aerosol vertical structures to refine model PBL representation, however, needs further explorations. Future reliable lidar data network measurements and advanced lidar data assimilation approaches will make high impacts on regional weather and air quality forecast.

\section{MULTI-PARAMETER LIDAR MEASUREMENTS TO SUPPORT ATMOSPHERIC PROCESS STUDY}

Supporting atmospheric process study has been one of the main lidar applications, but the values of individual atmospheric parameter measurements are limited now after knowledge gained from the past studies. Therefore, synergizing multiple lidar measurements is needed in the future. For air quality studies, multiwavelength elastic lidar measurements can provide aerosol size and type information. Vertical profiles of relative humidity and stability within the PBL from lidar water vapor and temperature measurements are needed to quantitatively interpret the observed variability in aerosol properties (Veselovskii et al., 2009). 
Aerosol-cloud interaction is one of the primary sources of uncertainties in future climate predictions. Ground-based multiple lidar measurements are critical to untangle the puzzle. Aerosol size and composition from multiwavelength lidar, vertical wind from Doppler Lidar, water vapor and temperature from Raman lidar or DIAL, and droplet concentrations retrieved from lidar cloud extinction measurements help to understand aerosol-cloud interactions for low-level clouds under different dynamical and thermodynamical conditions. Such multi-lidar measurements are needed under different aerosol and cloud conditions over multiple locations to fully understand aerosol-cloud interactions. For cloud studies, lidar multiple scattering (MS) is still a challenging issue. MS contains cloud microphysical and optical information (Donovan et al., 2015). Further exploring MS information together with lidar depolarization measurements could increase lidar capabilities to observe optically thick clouds.

PBL processes are still poorly understood and represented (National Academics of Sciences, 2018a; National Academics of Sciences, 2018b). The Land-Atmosphere Feedback Experiment (LAFE) deployed several state-of-the-art lidars at the ARM Climate Research Facility Southern Great Plains Megasite (SGP) to study land-atmosphere feedback (Wulfmeyer et al., 2018). LAFE demonstrated the power of multi-lidar measurements for the PBL study by providing simultaneous water vapor, temperature, aerosol, wind, and turbulence profiles. Besides ground-based multi-lidar observations, airborne multi-lidar observations are essential for critical atmospheric process studies by sampling where processes are happening. Aircrafts carrying lidars and radars can track a fast-moving storm to observe dynamical interactions (Liu et al., 2019). Compared with operational lidar applications, supporting atmospheric process study requires more powerful lidars to provide accurate measurements at fine temporal and spatial resolutions (Behrendt et al., 2015; Hammann et al., 2015; Lange et al., 2019).

\section{SYNERGIZING LIDAR WITH OTHER REMOTE SENSORS FOR ATMOSPHERIC CHARACTERIZATIONS}

Combining lidar with other active and passive sensor measurements offer new observational capabilities. Currently, lidar measurements are widely combined with cloud radar and radiometer measurements for cloud macro- and microphysical properties characterizations (Stephens et al., 2002; Wang and Sassen, 2002; Delanoë and Hogan, 2008; Deng et al., 2010; Wang et al., 2012). Synergizing lidar with other sensor measurements could advance atmospheric observation capabilities in many other frontiers (Nehrir et al., 2017). Although ground-based Raman and DIAL lidars can provide reliable vertical resolved water vapor and temperature profiles, these measurements are limited to below clouds when low or middle-level clouds are presented due to strong cloud attenuation (Turner et al., 2000). On the other hand, microwave radiometer profiler can provide all-weather measurements, but with coarse vertical resolutions (Zhang et al., 2018). Combining
Raman/DIAL lidar and microwave radiometer profiler measurements could offer improved all-weather water vapor and temperature profiling capabilities with multi-sensor optimization retrieval approaches (Turner and Blumberg, 2019). Similarly, the synergy of Doppler lidar and cloud radar measurements could offer in and out cloud wind fields to support many critical studies, such as cloud and environment interactions, especially combined with measurements from other types of lidars (Turk et al., 2020).

\section{LIDAR SYSTEMS FOR OCEAN MEASUREMENTS}

Oceans control the weather and climate globally and are poorly observed. Satellite ocean color measurements from passive visible sensors have provided a sustained synoptic view of the distribution of ocean optical properties and biogeochemical parameters, but lacking vertical information within the water column. Microwave and IR ocean observations from space only offer ocean surface properties due to strong water absorptions. Airborne lidars (Hoge and Swift, 1981; Churnside, 2014) have been used to study ocean subsurface properties for decades. CALIOP measurements demonstrated that space-borne elastic lidar signals could provide depth-resolved values of plankton properties globally (Lu et al., 2016). However, extract ocean particle information from elastic-only measurements is still challenging (Schulien et al., 2017). Ocean-optimized space lidars synergized with other ocean measurements (Hostetler et al., 2018; Chen et al., 2019; Jamet et al., 2019) would transform our ocean measurement capability. Further advancing lidar measurements with Brillouin scattering, Raman scattering, and fluorescence signals could provide ocean mixing layer temperatures, salinity, other chemical component information simultaneously, at least from airborne platforms (Hoge et al., 2005; de Lima Ribeiro et al., 2019).

\section{MULTI-SPECTRAL SURFACE AND VEGETATION MEASUREMENTS}

Multi - spectral lidar systems are expected to fill a major gap in land science by capturing at the same time two essential features: the $3 \mathrm{D}$ geometry of land targets and the type of observed surface through the spectral information. Morsy et al., (2017) demonstrated that the combination of building height and spectral information achieved a clearly higher accuracy than elevation data alone in mapping urban land cover. Retrieval of bathymetry using a single spectral channel is a well - established lidar application but opportunities for innovations remain significant, such as the integration of mono-spectral lidar with passive multi-spectral images to map coastal water (Zhang et al., 2019). Imaging, multi-spectral lidars combine differential water absorption with range measurements to map coastal waters and the land/water boundary very accurately (Morsy et al., 2018) 


\section{SPACE-BASED LIDAR FOR MEASUREMENTS BEYOND AEROSOL, CLOUDS, AND SURFACE HEIGHT}

Lidar measurements from CALIPSO, CATS, and ICESat satellites transformed our view of global aerosol, cloud, and ice sheet distributions (Winker et al. 2010; McGill et al. 2015; Yorks et al., 2016; Markus et al., 2017; Neumann et al., 2018; Neuenschwander and Pitts, 2019; Neumann et al., 2019). The latest NASA Earth science decadal survey recommends several missions requiring lidars to meet the science measurement objectives (National Academics of Sciences, 2018a). Global measurements of tropospheric wind, water vapor, $\mathrm{CO} 2$, temperature, and surface vegetation from space lidars will be highly desired (Baker et al., 2014; National Academics of Sciences, 2018a; National Academics of Sciences, 2018b), but there are challenges to overcome. ESA's Aeolus wind satellite was launched on August 22, 2018 and demonstrated the feasibility to measure wind from the space (Kanitz et al., 2020). Its fixed-beam pointing cannot provide wind speed and direction, however. Further technological advancements are needed to provide wind speed and direction measurements to better constrain weather models. DIAL lidars for water vapor and $\mathrm{CO} 2$ from space require high power lasers with stable narrow-line output, which are under development. Raman lidar is the only feasible lidar technique to provide fine vertical-resolved temperature profiles from space, but it requires high pulse energy $355 \mathrm{~nm}$ lasers with above $50 \mathrm{~W}$ power (Di Girolamo et al., 2018). There are multiple challenges in developing and operating such high energy UV lasers for a space-borne lidar. Lessons learned from Aeolus and EARTHCARE UV lidars should help future space-based Raman lidar development. NASA's PBL and Surface Topography and Vegetation (STV) incubation programs will accelerate future space-based new lidar developments. Although needs are different for different types of space-based lidars, developing high electrical-to-optical efficiency lasers and low-weight large telescope will benefit all space-based lidar applications.

\section{MINIATURIZATION AND PHOTON-COUNTING SURFACE LIDAR SYSTEMS}

The promise of photon-counting LIDAR is to deliver similar performance as traditional waveform - sampling systems at significantly reduced mass and power consumption. This may lead to a host of new applications, made feasible by far reaching miniaturization, but requires a fundamentally different approach to data processing and analysis. Threedimensional point clouds are widely used across a wide spectrum of applications from construction projects to forestry. Time-correlated single-photon counting (TCSPC) is a very active area of technological development. Multiple beam systems can improve substantially the accuracy of time-of-flight ranging and three-dimensional (3D) imaging, as demonstrated by Chen et al., (2018).

\section{BIOSPHERIC, CRYOSPHERIC AND HYDROLOGIC PROCESSES}

Multiple-beams and scanning systems are increasingly providing the measurements necessary to capture biospheric, cryospheric and hydrologic processes. Detailed 3D measurements of terrestrial vegetation over space and time are necessary but very scarce, thus making progress very hard in our understanding of the role of vegetation in the Earth System, particularly in the carbon and water cycle. It is not only the amount of vegetation that is of importance, but it is the detailed 3D structure of vegetation canopies (Menenti and Ritchie, 1994; Næsset, 1997; Straatsma and Baptist, 2008; Wang et al., 2009; Bucksch et al., 2014) to determine radiative and convective exchanges with the PBL (Faivre et al., 2017). Water - related morphometric features can be extracted from point - clouds generated by imaging lidars (see e.g. Koenders at al., 2014).

Notwithstanding its short life and sparse spatial coverage, the data acquired by GLAS on ICESat-1 have boosted unprecedented advances in understanding the response of alpine glaciers to climate forcing. The challenge ahead is to bring to fruition the far better capabilities of ATLAS on ICESat-2, while at the same time capturing the surface structure at a detail sufficient to understand mass transport within a glacier.

Accurate measurements of water level deliver unique global information on water storage and flow, thus filling a major gap in the observation of the terrestrial water cycle. LIDAR measurements of water level from space are inherently sparse in space and time, thus requiring innovative approaches to bring such information to fruition (Phan et al., 2012).

\section{INFRASTRUCTURE SURVEYS}

Monitoring and assessment of very diverse infrastructures require short - range LIDAR measurements at high accuracy and density (see e.g. Olsen et al., 2010), which leads to merge multiple point clouds acquired by terrestrial laser systems or very large pointclouds acquired by a moving and unstable platform (e.g. UAV). Developing efficient and accurate ways to create such large data sets while minimizing the degradation in data quality remains a very active area of research.

In structural engineering, accuracy required for change detection (or deformation measurement) or 3D object reconstruction is often sub-millimeter, generally about $5 \mathrm{~mm}$ or less. This requirement cannot always be met by the accuracy of the laser scanning point cloud from a single scan, and the accuracy of the point cloud from multiple scans is even worse. Moreover, removal of outliers and mixed pixels are also critical issues in identifying the real surface of an object. This is a major challenge in $3 \mathrm{D}$ object reconstruction. To meet this challenge a combination of solutions is needed, from technological developments in laser scanning to experimental protocols, passing through high performance data processing, especially for aligning large point clouds from multiple scans. 


\section{URBAN LANDSCAPE AND ENVIRONMENT}

Generation of 3D models of urban space is by now a mainstream application of scanning LIDAR systems ( $\mathrm{Pu}$ and Vosselman, 2009; Vosselman and Maas, 2010), but there is a clear trend towards the accurate representation of ever-increasing details within the built-up space, such as individual trees and signposts (Wang et al., 2017). This requires automatic recognition of objects, in addition to their very accurate and detailed representation. The challenge here is technological evolution towards miniaturization and autonomous data processing and concurrent advances in algorithms and their fundamentals. Recent UAV platforms jointly collect imagery and lidar data. Acquired 3D point clouds may achieve accuracies and resolutions of some millimeters, so far limited to terrestrial data capture. Further benefits of combined processing result from adding lidar range measurement to multi-view-stereo image matching during the generation of high-precision dense 3D point clouds.

A majority of the human population lives in urban and suburban areas. With increasing urbanization, urban meteorology and air quality have become an emerging area of great interest. How the properties of urban environments modify the PBL structure and impact urban weather and air quality is a largely unresolved question (National Research Council, 2012). There remain numerous scientific, technical and computational challenges to improving urban weather and air quality forecasting. Understanding urban PBL properties and processes is crucial. Over urban street canyons, characterized by different scale inhomogeneities regarding the surface type and terrain height, modern understanding of PBL physics and

\section{REFERENCES}

Bösenberg, J., and Hoff, R. (2007). Plan for the implementation of the GAW aerosol lidar observation network GALION (Hamburg, Germany, 27-29 March 2007) GAW Report 178. Geneva, Switzerland: WMO.

Baker, W. E., Atlas, B., Cardinali, C., Clement, A., Emmitt, G. D., Gentry, B. M., et al. (2014). Lidar-measured wind profiles: the missing link in the global observing system. B. Am. Meteorol. Soc. 95, 543-564. doi:10.1175/BAMS-D-1200164.1

Barlow, J. F. (2014). Progress in observing and modelling the urban boundary layer. Urban Clim. 10, 216-240. doi:10.1016/j.uclim.2014.03.011

Behrendt, A., Wulfmeyer, V., Hammann, E., Muppa, S. K., and Pal, S. (2015). Profiles of second- to third-order moments of turbulent temperature fluctuations in the convective boundary layer: first measurements with rotational Raman lidar. Atmos. Chem. Phys., 15, 5485-5500. doi:10.5194/ acp-15-5485-2015

Bos, R., Giyanani, A., and Bierbooms, W. (2016). Assessing the severity of wind gusts with lidar. Rem. Sens. 8, 758. doi:10.3390/rs8090758

Bucksch, A., Lindenbergh, R. C. L., Abd Rahman, M. Z., and Menent, M. (2014). Breast height diameter estimation from high-density airborne LiDAR data. Geosci. Rem. Sens. Lett. IEEE 11 (6), 1056-1060. doi:10.1109/LGRS.2013. 2285471

Chen, G., Tang, J., Zhao, C., Wu, S., Yu, F., Ma, C., et al. (2019). Concept design of the "guanlan" science mission: China's novel contribution to space oceanography, Frontiers in Marine 6, 194. doi:10.3389/fmars.2019.00194

Chen, Z. D., Fan, R. W., Li, X. D., Dong, Z. W., Zhou, Z. G., Ye, G. C., et al. (2018). Accuracy improvement of imaging lidar based on time-correlated single- parameterization is not sufficient for urban applications (Kukkonen et al., 2012; Zhang et al., 2012). Although there are various ways to provide near-surface observations, these are not sufficient in identifying and quantifying the physical processes that drive the urban PBL (Muller et al., 2013). The upper 90\% of the urban boundary layer remains under-researched (Barlow, 2014). Regional lidar networks with multi-type lidar systems could fill the data gap to enhance urban PBL process studies and improve urban environment predication.

\section{SUMMARY}

Future lidar applications can go beyond the traditional fields discussed above. Short-range 2-D/3-D lidar advanced rapidly driven by autonomous vehicle development needs. Further developments of all-fiber lidar could provide a reliable and cost-effective way to detect turbulence, wind shear, volcanic ash, supercooled liquid clouds with icing risks, and high ice water content clouds from aircraft in real-time to support safe aircraft operations (Schmitt, 2017; Thobois et al., 2019). If we successfully meet these challenges, lidar measurements from ground, aircraft, and satellite will continuously transform our capability to support earth system science study and power new lidar applications.

\section{AUTHOR CONTRIBUTIONS}

$\mathrm{ZW}$ and MM work collaboratively on this grand challenge paper in lidar sensing.

photon counting using three laser beams. Optic Commun. 429, 175-179. doi:10.1016/j.optcom.2018.08.017

Cheng, X., Liu, Y., Xu, X., You, W., Zang, Z., Gao, L., et al. (2019). Lidar data assimilation method based on CRTM and WRF-Chem models and its application in PM2.5 forecasts in Beijing. Sci. Total Environ. 682, 541-552. doi:10.1016/j.scitotenv.2019.05.186

Chipilski, H. G., Wang, X., and Parsons, D. B. (2019). Impact of assimilating pecan profilers on the prediction of bore-driven nocturnal convection: a multi-scale forecast evaluation for the 6 July 2015 case study. Monthly Weather Rev. 148, 171. doi:10.1175/MWR-D-19-0171.1

Chu, X., and Yu, Z. (2017). Formation mechanisms of neutral Fe layers in the thermosphere at Antarctica studied with a thermosphere-ionosphere $\mathrm{Fe} / \mathrm{Fe}+$ (TIFe) model. J. Geophys. Res. Space Phys. 122, 23773. doi:10.1002/2016JA023773

Churnside, J. H. (2014). Review of profiling oceanographic lidar. Opt. Eng. 53, 051405. doi:10.1117/1.OE.53.5.051405

Colin, J., Faivre, R., and Menenti, M. (2010). Aerodynamic roughness length estimation from very high-resolution imaging LIDAR observations over the Heihe basin in China. Hydrol. Earth Syst. Sci. Discuss. 7, 3397-3421. doi:10. 5194/hessd-7-3397-2010

Cooney, J. (1968). Measurements on the Raman component of laser atmospheric backscatter. App. Phys. Letters 12, 40-42. doi:10.1063/1.1651884

de Lima Ribeiro, A., Artlett, C., and Pask, H. (2019). A LIDAR-compatible, multichannel Raman spectrometer for remote sensing of water temperature. Sensors 19, 2933. doi:10.3390/s19132933

De Mazière, M., Thompson, A. M., Kurylo, M. J., Wild, J. D., Bernhard, G., Blumenstock, T., et al. (2018). The network for the detection of atmospheric composition change (NDACC): history, status and perspectives, Atmos. Chem. Phys. 18, 4935-4964. doi:10.5194/acp-18-4935-2018 
Delanoë, J., and Hogan, R. J. (2008). A variational scheme for retrieving ice cloud properties from combined radar, lidar and infrared radiometer. J. Geophys. Res. 113 (D7), D07204. doi:10.1029/2007JD009000

Deng, M., Mace, G. G., Wang, Z., and Okamoto, H., (2010). TC ${ }^{4}$ validation for ice cloud profiling retrieval using CloudSat radar and CALIPSO lidar, J. Geophys. Res. 115, D00J15. doi:10.1029/2009JD013104

Di Girolamo, P., Behrendt, A., and Wulfmeyer, V. (2018). Space-borne profiling of atmospheric thermodynamic variables with Raman lidar: performance simulations. Optic Express 26, 8125-8161. doi:10.1364/OE.26.008125

Donovan, D. P., Klein Baltink, H., Henzing, J. S., de Roode, S. R., and Siebesma, A. P. (2015). A depolarisation lidar-based method for the determination of liquidcloud microphysical properties, Atmos. Meas. Tech. 8, 237-266. doi:10.5194/ amt-8-237-2015

El Amraoui, L., Sič, B., Piacentini, A., Marécal, V., Attié, J.-L., and Frebourg, N. (2020). Aerosol data assimilation in the chemical transport model MOCAGE during the TRAQA/ChArMEx campaign: lidar observations, Atmos. Meas. Tech. Discuss 13, 4645-4667. doi:10.5194/amt-2019-482

Engelmann, R., Kanitz, T., Baars, H., Heese, b., Althausen, D., Skupin, A., et al. (2016). The automated multiwavelength Raman polarization and water-vapor lidar PollyXT: the neXT generation. Atmos. Meas. Tech. 9, 1767-1784. doi:10. 5194/amt-9-1767-2016

Faivre, R., Colin, J., and Menenti, M. (2017). Evaluation of methods for aerodynamic roughness length retrieval from very high-resolution imaging LIDAR observations over the Heihe basin in China. Rem. Sens. 9 (1), 63-87. doi:10.3390/rs9010063

Fiocco, G., and Smullin, L. D. (1963). Detection of scattering layers in the upper atmosphere $(60-140 \mathrm{~km})$ by optical radar. Nature 199 (4900), 1275-1276.

Goldsmith, J. E. M., Blair, F. H., Bisson, S. E., and Turner, D. D. (1998). Turn-key Raman lidar for profiling atmospheric water vapor, clouds, and aerosols. Appl. Optic. 37, 4979-4990. doi:10.1364/ao.37.004979

González-Jorge, H., Martínez-Sánchez, J., Bueno, M., and Arias, P. (2017). Unmanned aerial systems for civil applications: a review. Drones 1, 2. doi:10.3390/drones101000Koenders

Hammann, E., Behrendt, A., Le Mounier, F., and Wulfmeyer, V. (2015). Temperature profiling of the atmospheric boundary layer with rotational Raman lidar during the $\mathrm{HD}(\mathrm{CP})^{2}$ observational prototype experiment. Atmos. Chem. Phys. 15, 2867-2881. doi:10.5194/acp-15-2867-2015

Hicks, M., Demoz, B., Vermeesch, K., and Atkinson, D. (2019). Intercomparison of mixing layer heights from the national weather service ceilometer test sites and collocated radiosondes. J. Atmos. Oceanic Technol., 36, 129-137. doi:10.1175/ JTECH-D-18-0058.1

Hoge, F. E., Lyon, P. E., Wright, C. W., Swift, R. N., and Yungel, J. K. (2005). Chlorophyll biomass in the global oceans: airborne lidar retrieval using fluorescence of both chlorophyll and chromophoric dissolved organicmatter. Appl. Optic. 44, 2857-2862. doi:10.1364/ao.44.002857

Hoge, F. E., and Swift, R. N. (1981). Airborne simultaneous spectroscopic detection of laser-induced water Raman backscatter and fluorescence from chlorophyll a and other naturally occurring pigments. Appl. Optic. 20, 3197-3205. doi:10. 1364/AO.20.003197

Hostetler, C. A., Behrenfeld, M. J., Hu, Y., Hair, J. W., and Schulien, J. A. (2018). Spaceborne lidar in the study of marine systems. Annu. Rev. Mar. Sci. 10, 121-147. doi:10.1146/annurev-marine-121916-063335

Jamet, C., Ibrahim, A., Ahmad, Z., Angelini, F., Babin, M., Behrenfeld, M. J., et al. (2019). Going beyond standard ocean color observations: lidar and polarimetry, Frontiers in Marine Science 6, 251. doi:10.3389/fmars.2019.00251

Kanitz, T., Ciapponi, A., Mondello, A., D’Ottavi, A., Baselga, A., Mateo, A. B., et al. (2020). ESA's lidar missions Aeolus and EarthCARE. EPJ 237, 01006. doi:10. 1051/epjconf/202023701006

Kashani, A., Olsen, M., Parrish, C., and Wilson, N. (2015). A review of lidar radiometric processing: from $\mathrm{AD}$ HOC intensity correction to rigorous radiometric calibration. Sensors 15, 28099. doi:10.3390/s151128099

Kawabata, T., Iwai, H., Seko, H., Shoji, Y., Saito, K., Ishii, S., et al. (2014). Cloudresolving $4 \mathrm{D}$-Var assimilation of Doppler wind lidar data on a meso-gammascale convective system. Mon. Weather Rev. 142, 4484-4498. doi:10.1175/ MWR-D-13-00362.1

Koenders, R., Lindenbergh, R. C., Storms, J. E. A., and Menenti, M. (2014). Multiscale curvatures for identifying channel locations from DEMs. Comp. Geosci. Intern. j. 68, 11-21. doi:10.1016/j.cageo.2014.03.016
Krishnamurthy, R., Choukulkar, A., Calhoun, R., Fine, J., Oliver, A., Barr, K. S., et al. (2012). Coherent Doppler lidar for wind farm characterization. Wind Energy 16, 189-206. doi:10.1002/we.539

Kukkonen, J., Olsson, T., Schultz, D. M., Baklanov, A., Klein, T., Miranda, A. I., et al. (2012). A review of operational, regional-scale, chemical weather forecasting models in Europe. Atmos. Chem. Phys. 12, 1-87. doi:10.5194/ acp-12-1-2012

Lange, D., Behrendt, A., and Wulfmeyer, V. (2019). Compact operational tropospheric water vapor and temperature Raman lidar with turbulence resolution. Geophys. Res. Lett. 46, 14844-14853. doi:10.1029/2019GL085774

Langford, A. O., Alvarez, R. J., Brioude, J., Evan, S., Iraci, L. T., Kirgis, G., et al. (2018). Coordinated profiling of stratospheric intrusions and transported pollution by the tropospheric ozone lidar network (TOLNet) and NASA alpha Jet experiment (AJAX): observations and comparison to HYSPLIT, RAQMS, and FLEXPART, atmos. Environ. Times 174, 1-14. doi:10.1016/j. atmosenv.2017.11.031

Leuenberger, D., Alexander, H., Omanovic, N., Fengler, Martin., Martucci, Giovanni., Bertrand, C., et al. (2020). Improving high-impact numerical weather prediction with lidar and drone observations, Bull. Amer. Meteor. Soc. 101 (7), E1036-E1051. doi:10.1175/BAMS-D-19-0119.1

Liu, Z., Barlow, J. F., Chan, P.-W., Fung, J. C. H., Li, Y., Ren, C., et al. (2019). A review of progress and applications of pulsed Doppler wind LiDARs. Remote Sens. 11, 2522. doi:10.3390/rs11212522

Lu, X. M., Hu, Y. X., Pelon, J., Trepte, C., Liu, K., Rodier, S., et al. (2016). Retrieval of ocean subsurface particulate backscattering coefficient from space-borne CALIOP lidar measurements. Opt. Express 24, 29001-29008. doi:10.1364/ OE.24.029000

Maiman, T. H. (1960). Stimulated optical radiation in ruby. Nature 187, 493-494.

Mariage, V., Pelon, J., Blouzon, F., Victori, S., Geyskens, N., Amarouche, N., et al. (2017). IAOOS microlidar-on-buoy development and first atmospheric observations obtained during 2014 and 2015 arctic drifts. Optic Express 25 (4), A73-A84. doi:10.1364/OE.25.000A73

Markus, T., Neumann, T., Martino, A., Abdalati, W., Brunt, K., Csatho, B., et al. (2017). The Ice, Cloud, and land Elevation Satellite-2 (ICESat-2): science requirements, concept, and implementation. Remote Sens. Environ. 190, 260-273. doi:10.1016/j.rse.2016.12.029

McGill, M. J., Yorks, J. E., Scott, V. S., Kupchock, A. W., and Selmer, P. A. (2015). The cloud-aerosol transport system (CATS): a technology demonstration on the international space station, Proc. Spie. 9612, 2190841. doi:10.1117/12.2190841

Melfi, S. H., Lawrence, J. D., and McCormick, M. P. (1969). Observation of Raman scattering by water vapor in the atmosphere. Appl. Phys. Lett. 15, 295-297. doi:10.1063/1.1653005

Menenti, M., and Ritchie, J. C. (1994). Estimation of effective aerodynamic roughness of Walnet Gulch watershed with laser altimeter measurements. Water Resour. Res. 30, 1329-1337. doi:10.1029/93WR03055

Morsy, S., Shaker, A., and El-Rabbany, A., (2017). Multispectral LiDAR data for land cover classification of urban areas. Sensors 17, 958-978. doi:10.3390/ s17050958

Morsy, S., Shaker, A., and El-Rabbany, A., (2018). Using multispectral airborne LiDAR data for land/water discrimination: a case study at lake ontario, Canada. Appl. Sci. 8, 349-369. doi:10.3390/app8030349

Muller, C. L., Chapman, L., Grimmond, C. S. B., Young, D. T., and Cai, X., (2013). Sensors and the city: a review of urban meteorological networks. Int. J. Climatol. 33, 1585-1600. doi:10.1002/joc.3678

Næsset, E. (1997). Determination of mean tree height of forest stands using airborne laser scanner data. ISPRS J. Photogram. Rem. Sensing 52 (2), 49-56. doi:10.1016/S0924-2716(97)83000-6

National Academies of Sciences, (2018a). Engineering, and medicine Thriving on our changing planet: a decadal strategy for earth observation from space. Washington, DC: The National Academies Press. doi:10.17226/24938

National Academies of Sciences, (2018b). Engineering, and medicine (NASEM), The future of atmospheric boundary layer observing, understanding, and modeling: Proceedings of a Workshop. Washington, DC: National Academies Press. doi:10.17226/25138

National Research Council (2012). Urban meteorology: Forecasting, monitoring, and meeting Users' needs. Washington, DC: National Academies Press, 190. Available online at http://www.nap.edu/ openbook.php?record_id=13328. 
National Research Council, (2009). Committee on developing mesoscale Meteorological observational capabilities to meet multiple National needs," observing weather and climate from the ground up: a nationwide network of networks Washington, D.C: National Academies Press, 234.

Nehrir, A. R., Kiemle, C., Lebsock, M. D., Kirchengast, G., Buehler, S. A., Lohnert, U., et al. (2017). Emerging technologies and synergies for airborne and spacebased measurements of water vapor profiles. Surv. Geophys. 38, 1445-1482. doi:10.1007/s10712-017-9448-9

Nehrir, A. R., Repasky, K. S., and Carlsten, J. L. (2011). Eye-safe diode-laser-based micropulse differential absorption lidar (DIAL) for water vapor profiling in the lower Troposphere. J. Atmos. Oceanic Technol. 28 (2), 131-147. doi:10.1175/ 2010JTECHA1452.1

Neuenschwander, A., and Pitts, K. (2019). The ATL08 land and vegetation product for the ICESat-2 Mission. Remote Sens. Environ. 221, 247-259. doi:10.1016/j. rse.2018.11.005

Neumann, T., Brenner, A., Hancock, D., Robbins, J., Saba, J., and Harbeck, K. (2018). ICE, CLOUD, and land elevation satellite - 2 (ICESat-2) project algorithm theoretical basis document (ATBD) for global geolocated photons ATL03. Greenbelt, Maryland: NASA Goddard Space Flight Center.

Neumann, T., Martinoa, A. J., Markusa, T., Bae, S., Bock, M. R., Brenner, A. C., et al. (2019). The ice, cloud and land elevation satellite-2 mission: a global geolocated photon product. Remote Sens. Environ. 233, 111325. doi:10.1016/j. rse.2019.111325

Olsen, M. J., Kuester, F., Chang, B. J., and Hutchinson, T. C. (2010). Terrestrial laser scanning-based structural damage assessment. J Comp in Civ. Eng. 24 (3), 264-272. doi:10.1061/(ASCE)CP.1943-5487.0000028

Pappalardo, G., Amodeo, A., Apituley, A., Comeron, A., Freudenthaler, V., Linné, H., et al. (2014). EARLINET towards an advanced sustainable European aerosol lidar network. Atmos. Meas. Tech. 7, 2389-2409. doi:10.5194/amt-7-2389-2014

Perr-Sauer, J., Tripp, C., Optis, M., and King, J. (2020). Short-term wind forecasting using statistical models with a fully observable wind flow, J. Phys.: Conf. Ser. 1452, 012083. doi:10.1088/1742-6596/1452/1/012083

Phan, V. H., Lindenbergh, R. C., and Menenti, M. (2012). ICESat derived elevation changes of Tibetan lakes between 2003 and 2009. Int. J. Appl. Earth Obs. Geoinf. 17, 12-22. doi:10.1016/j.jag.2011.09.015

$\mathrm{Pu}, \mathrm{S}$., and Vosselman, G., (2009). Knowledge based reconstruction of building models from terrestrial laser scanning data. ISPRS J. Photogrammetry Remote Sens. 64 (6), 575-585. doi:10.1016/j.isprsjprs.2009.04.001

$\mathrm{Pu}, \mathrm{Z}$., Zhang, L., and Emmitt, G. D., (2010). Impact of airborne Doppler wind lidar profiles on numerical simulations of a tropical cyclone. Geophys. Res. Lett. 37, L05801. doi:10.1029/2009GL041765

Reichardt, J., Wandinger, U., Klein, V., Mattis, I., Hilber, B., and Begbie, R., (2012). RAMSES: German Meteorological Service autonomous Raman lidar for water vapor, temperature, aerosol, and cloud measurements. Appl Opt. 51, 8111-8131. doi:10.1364/AO.51.008111

Roca, D., Martínez-Sánchez, J., Lagüela, S., and Arias, P. (2016). Novel aerial 3D mapping system based on UAV platforms and 2D laser scanners. J. Sensors 2016, 1-8. doi:10.1155/2016/4158370

Schmitt, N. P. (2017). "Research results, lessons learned and future perspective of forward-looking LIDAR for aircraft," in CLEO conference laser science to photonic applications, Conference on Lasers and Electro-Optics (CLEO), San Jose, CA, May 14-19, 2017. doi:10.1364/ CLEO_AT.2017.AM1A.2

Schotland, R. M. (1966). Some observations of the vertical profile of water vapor by a laser optical radar, in Proc. 4th symposium on remote sensing of environment, Ann Arbor: University of Michigan, 12-14, 273-283.

Schulien, J. A., Behrenfeld, M. J., Hair, J. W., Hostetler, C. A., and Twardowski, M. S. (2017). Vertically-resolved phytoplankton carbon and net primary production from a high spectral resolution lidar. Opt. Express 25, 13577-13587. doi:10.1364/OE.25.013577

Smullin, L. D., and Fiocco, G. (1962). Optical echoes from moon. Nature. 194 (4835), 1267. doi:10.1038/1941267a0

Stephens, G. L., Vane, D. G., Boain, R., Mace, G. G., Sassen, K., and Wang, Z. (2002). The CloudSat mission and the EOS constellation: a new dimension of space-based observations of clouds and precipitation. Bull. Amer. Meteor. Soc. 83, 1771-1790.

Stillwell, R. A., Spuler, S. M., Hayman, M., Repasky, K. S., and Bunn, C. E. (2020). Demonstration of a combined differential absorption and high spectral resolution lidar for profiling atmospheric temperature. Optic Express 28, 71-93. doi:10.1364/OE.379804

Straatsma, M. W., and Baptist, M. J. (2008). Floodplain roughness parameterization using airborne laser scanning and spectral remote sensing. Remote Sensing of Environment 112 (3), 1062-1080. doi:10.1016/j.rse.2007. 07.012

Sugimoto, N., Nishizawa, T., Shimizu, A., and Jin, Y. (2016). The asian Dust and aerosol lidar observation network (AD-Net). EPJ 119, 19001. doi:10.1051/ epjconf/201611919001

Thobois, L., Cariou, J. P., and Gultepe, I. (2019). Review of lidar-based applications for aviation weather. Pure Appl. Geophys. 176, 1959-1976. doi:10.1007/s00024018-2058-8

Turk, F. J., Hristova-Veleva, S., Durden, S. L., Tanelli, S., Sy, O., Emmitt, G. D., et al. (2020). Joint analysis of convective structure from the APR-2 precipitation radar and the DAWN Doppler wind lidar during the 2017 Convective Processes Experiment (CPEX), Atmos. Meas. Tech. 13, 4521-4537. doi:10.5194/amt-134521-2020

Turner, D. D., Feltz, W. F., and Ferrare, R. A. (2000). Continuous water vapor profiles from operational ground-based active and passive remote sensors. $B$. Am. Meteorol. Soc. 8, 1301-1317. doi:10.1175/1520-0477(2000)081<1301: CWBPFO $>2.3 . \mathrm{CO} ; 2$

Turner, D. D., and Blumberg, W. G., (2019). Improvements to the AERIoe thermodynamic profile retrieval algorithm. IEEE J. Sel. Top. Appl. Earth Obs. Remote Sens. 12, 1939-1404. doi:10.1109/JSTARS.2018.2874968

Veselovskii, I., Whiteman, D. N., Kolgotin, A., Andrews, E., and Korenskii, M. (2009). Demonstration of aerosol property profiling by multi-wavelength lidar under varying relative humidity conditions. J. Atmos. Ocean. Technol. 26, 1543-1557. doi:10.1175/2009JTECHA1254.1

Vosselman, G., and Maas, H.-G. (2010). Airborne and terrestrial laser scanning. ISBN 978-1904445-87-6 CRC Press, Boca Raton: 318 p

Wang, C., Menenti, M., Stoll, M. P., Feola, A., Belluco, E., and Marani, M. (2009). Separation of ground and low vegetation signatures in LIDAR measurements of salt-marsh environments. IEEE Trans. Geosci. Remote Sens. 47, 2014-2023. doi:10.1109/TGRS.2008.2010490

Wang, J. H., González-Jorge, H., Lindenbergh, R. C., Arias-Sánchez, P., and Menenti, M. (2013). Automatic estimation of excavation volume from laser mobile mapping data for mountain road widening. Rem. Sens. 5 (9), 4629-4651. doi: $10.3390 /$ rs5094629

Wang, J. H., Lindenbergh, R., and Menenti, M. (2017). SigVox-A 3D feature matching algorithm for automatic street object recognition in mobile laser scanning point clouds. ISPRS J. Photogrammetry Remote Sens. 128, 111-129. doi:10.1016/j.isprsjprs.2017.03.012

Wang, Z., French, J., Vali, G., Wechsler, P., Haimov, S., Rodi, A., et al. (2012). Single aircraft integration of remote sensing and in situ sampling for the study of cloud microphysics and dynamics. BAMS 93, 653-766. doi:10.1175/BAMS-D-1100044.1

Wang, Z., and Sassen, K. (2002). Cirrus cloud microphysical property retrieval using lidar and radar measurements. Part I: algorithm description and comparison with in situ data J. Appl. Meteorol. 41 (3), 218-229. doi:10. 1175/1520-0450(2002)041<0218:CCMPRU >2.0.CO;2

Weckwerth, T. M., Weber, K. J., Turner, D. D., and Spuler, S. M., (2016). Validation of a water vapor micropulse differential absorption lidar (dial), J. Atmospheric Ocean. Technol. 33 (11), 2353-2372. doi:10.1175/JTECH-D-16-0119.1

Weitkamp, C. (2005). Lidar Range-resolved optical remote sensing of the atmosphere, in The Springer Series in optical sciences. Singapore: Springer, 102. doi: $10.1007 / \mathrm{b} 106786$

Welton, E. J., Campbell, J. R., Spinhirne, J. D., and Stanley Scott, V. (2001). Global monitoring of clouds and aerosols using a network of micropulse lidar systems. SPIE Conf. Proc. 4153, 151-158. doi:10.1117/12.417040

Winker, D. M., Pelon, J., Coakley, J. A., Jr., Ackerman, S. A., Charlson, R. J., Colarco, P. R., et al. (2010). The CALIPSO mission: a global 3D view of aerosols and clouds. Bull. Am. Meteorol. Soc. 91, 1211-1229. doi:10.1175/ 2010BAMS3009.1

Woodbury, E. J., Congleton, R. S., Morse, J. H., and Stitch, M. L. (1961). Design and operation of an experimental Colidar. IRE WESCON Convention.

Wu, D., Wang, Z., Wechsler, P., Mahon, N., Deng, M., Glover, B., et al. (2016). Airborne compact rotational Raman lidar for temperature measurement. Opt. Express 24 (18), A1210-A1223. doi:10.1364/OE.24.0A1210 
Wulfmeyer, V., Turner, D., and Baker, B., Banta, R., Behrendt, A., Bonin, T., et al. (2018). A new research approach for observing and characterizing landatmosphere feedback." Bull. Am. Meteorol. Soc., 99 (8), 0009. doi:10.1175/ BAMS-D-17-0009.1

Wulfmeyer, V., Bauer, H.-S., Grzeschik, M., Behrendt, A., Vandenberghe, F., Browell, E. V., et al. (2006). Four-dimensional variational assimilation of water vapor differential absorption lidar data: the first case study within IHOP_2002, Mon. Weather Rev. 134 (1), 209-230. doi:10.1175/ MWR3070.1

Wulfmeyer, V., Hardesty, R. M., Turner, D. D., Behrendt, A., Cadeddu, M. P., Di Girolamo, P., et al. (2015). A review of the remote sensing of lower tropospheric thermodynamic profiles and its indispensable role for the understanding and the simulation of water and energy cycles. Rev. Geophys. 53 (3), 819-895. doi:10. 1002/2014RG000476

Würth, I., Valldecabres, L., Simon, E., Mhrlen, C., Uzunoglu, B., Gilbert, C., et al. (2019). Minute-scale forecasting of wind power-results from the collaborative workshop of IEA wind task 32 and 36. Energies 12 (4), 712. doi:10.3390/ en12040712

Yorks, J. E., McGill, M. J., Palm, S. P., Hlavka, D. L., Selmer, P. A., Nowottnick, E. P., et al. (2016). An overview of the CATS level 1 processing algorithms and data products. Geophys. Res. Lett., 43, 4632-4639. doi:10.1002/ 2016GL068006
Zhang, J., Zuidema, P., Turner, D. D., and Cadeddu, M. P. (2018). Surface-based microwave humidity retrievals over the equatorial Indian Ocean: applications and challenges. J. Appl. Meteor. Climatol. 57, 1765-1782. doi:10.1175/JAMC-D17-0301.1

Zhang, Y., Bocquet, M., Mallet, V., Seigneur, C., and Baklanov, A. (2012). Real-time air quality forecasting, part II: state of the science, current research needs, and future prospects. Atmos. Environ. 60, 656-676. doi:10.1016/j.atmosenv.2012. 02.041

Zhang, Z., Zhang, J. Y., Ma, Y., Tian, H. B., and Jiang, T., (2019). Retrieval of nearshore bathymetry around ganquan island from LiDAR waveform and QuickBird image. Appl. Sci. 9, 4375-4391. doi:10.3390/app9204375

Conflict of Interest: The authors declare that the research was conducted in the absence of any commercial or financial relationships that could be construed as a potential conflict of interest.

Copyright (c) 2021 Wang and Menenti. This is an open-access article distributed under the terms of the Creative Commons Attribution License (CC BY). The use, distribution or reproduction in other forums is permitted, provided the original author(s) and the copyright owner(s) are credited and that the original publication in this journal is cited, in accordance with accepted academic practice. No use, distribution or reproduction is permitted which does not comply with these terms. 